\title{
Approaches to the selection of the most effective corrosion inhibitors in JSC Gazprom Neft
}

\author{
Kunakova Anisa ${ }^{1, *}$, Sayfutdinova Liniza $^{1}$, Yampurov Vladimir ${ }^{2}$, Gogoleva Alexandra ${ }^{3}$ \\ ${ }^{1}$ Gazprom Neft STC LLC, Russia \\ ${ }^{2}$ JSC Gazprom Neft, Russia \\ ${ }^{3}$ Ufa State Petroleum Technological University, Russia
}

\begin{abstract}
The article considers an approach to the selection of reagents for protecting pipelines from corrosion. The report gives a list of required laboratory tests. This allows to identify effective corrosion inhibitors for their further field tests. The implementation of the approach driving tangible buisness benefits.
\end{abstract}

\section{Introduction}

Ensuring the reliability and durability of the equipment and pipeline systems is crucial task in the extraction, transportation and processing of hydrocarbon raw material. Approximately one quarter of all metal produced in the world is lost through the corrosion processes every year. Anti-corrosion protection is one of the most important tasks in the oil industry, purpose of which is not only to ensure the safety and durability of metal structures, but also to prevent possible negative effects on the environment.

Corrosion reduces lifespan of steel equipment and pipelines, increases the cost of repairing them, and may cause serious environmental damage. Cost of repair and replacement of equipment and chemical production communications are often several times higher than the cost of materials of which they are made [1].

It is clear that corrosion is the deterioration of metals and various alloys as a result of chemical or electrochemical reactions between it and the surrounding environment [2]. Under the conditions of extraction and transportation of hydrocarbon raw materials, very hostile environments is determined by the presence of aggressive gases (hydrogen sulfide, carbon dioxide and oxygen), as well as the presence of the aqueous phase and its physicochemical properties $(\mathrm{pH}$, temperature and mineralization). The presence of corrosive gases in the product leads to corrosive destruction of steel equipment and pipelines in the process of extraction, purification, transportation and processing of hydrocarbon raw materials. Currently, there are various ways of corrosion protection, as using of equipment from corrosionresistant steels, pipelines with a covering, electrochemical protection, as well as chemical methods [3].

The use of corrosion inhibitors is the one of the most cost-effective and practical means of protecting against corrosion for number of reasons. First, corrosion inhibitors can be applied in the later stages of field development when the water content of the produced oil increases. Secondly, the use of inhibitors does not imply changes in the technological process of production, preparation and transportation of oil. Thirdly, corrosion inhibitors can be injected at the starting point of the movement of the produced products and provide protection along the entire oil transport route, protecting the metal from the corrosive environment and preventing the formation of corrosive damage. Finally, corrosion inhibitors can be used to protect equipment that has been in operation for a long time, making it economically beneficial.

\section{Prerequisites for the development of a methodology for the use of corrosion inhibitors}

Currently, there are more than 130 oilfield chemical companies of Russia developing and producing chemical reagents, including corrosion inhibitors. JSC Gazprom Neft open for all new efficient technologies and related chemical reagents, furthermore the company is based on the principles of fair competition. JSC Gazprom Neft pays great attention to corrosion issues and is interested in the absence of complications in the production, transportation and preparation of oil, gas and water.

Previously, only one or three types of corrosion inhibitors were used at corrosion-complicated facilities in the extractive subsidiaries of JSC Gazprom Neft. Systematic studies of all possible corrosion factors were not conducted and were not analyzed, also limiting ones were not identified. Alternative options and methods were not taken into account. The market of chemical reagent manufacturers was not investigated enough.

Over the last 5-7 years, Gazprom Neft JSC has been conducting a systematic study of corrosion on

\footnotetext{
${ }^{*}$ Corresponding author: Kunakova.AM $@$ gazpromneft-ntc.ru
} 
equipment, the study of corrosion-effective elements and the selection of technological and cost-effective methods of dealing with corrosion.

Over the past period, significant work has been done to study the problems of corrosion on equipment, classifiers of corrosion damage and factors of their formation were developed. Internal guidelines and methodological documents describing the processes of selection technologies, chemical reagents and organizing of control over the implementation of anti-corrosion activities have been developed and put into action.

Now, a comprehensive study and analysis of all possible factors that have led to the corrosion is carried out. Based on a thorough analysis of information, laboratory tests determine the most significant, limiting factors are determined on the basis of a thorough analysis of information, laboratory tests. Limiting factors lead to corrosive destruction of specific objects operating in specific conditions and modes. Targeted solutions and methods are being developed to prevent corrosion in the future, to establish a monitoring system for the prompt detection of corrosion processes.

To date, a great work on testing of a large number of reagents has been done. As a result, a wide range of corrosion inhibitors has been selected and is already being used in the fields. Also, the range of corrosion inhibitors approved for industrial use has grown and is no less than 7-12 reagents, mainly Russian-made.

Prerequisites for expanding the number and range of corrosion inhibitors were several factors. Firstly, the implementation of the "Clean Territory" program, consisting of a set of measures aimed at improving the integrity and reliability of the Company's pipeline systems. Secondly, the need to create a competitive environment in the implementation of procedures for the purchase of reagents. Thirdly, the need to establish and implement in the Company common principles and approaches for conducting laboratory and pilot tests of corrosion inhibitors.

\section{Development of normative and methodological documents of JSC Gazprom Neft}

\subsection{Technical requirements for corrosion inhibitors and development of laboratory test algorithm}

JSC Gazprom Neft developed a number of documents that structured the process and established uniform rules and requirements. As a result of the introduction of the basic Standard of the Company "Chemicalization of Production Processes" and the Standard for the process "Input Quality Control of Chemical Reagents Used in Technological Processes of Oil Production", technical requirements were set for all groups of chemical reagents, including in technological processes of extraction, collection, preparation and transportation of oil. The company formalized and approved the requirements for laboratory testing of reagents. It also approved the requirements for the determination of their physico-chemical characteristics for the implementation of the input quality control procedures used in the Company's chemical reagents. The allowable range of values and the method of its determination are set for each parameter tested.

In accordance with the internal procedure adopted in the Block of Exploration and Production, all chemical reagents on a general basis undergo two-step tests, including laboratory and the field tests.

Laboratory tests carried out according to an approved plan. The testing of a set of physicochemical parameters that are technologically significant for production processes takes place in stages.

Reagents undergo a preliminary anonymization procedure prior to the start of laboratory tests in order to ensure objectivity and selection of effective corrosion inhibitors for the conditions of a particular complicated object. Representatives of the testing laboratory are not involved in the process of depersonalization. Laboratory tests are carried out exclusively with impersonal reagents. Decryption of anonymized reagents is carried out only after completion and approval of the final report with the results of laboratory tests so that they cannot be changed.

One of the most important requirements for corrosion inhibitors is to ensure the effectiveness of the protective action - at least $90 \%$. In determining the effectiveness of corrosion inhibitors, inhibitors that exhibit protective properties against general corrosion are detected primarily by the LPR method. Effective reagents, depending on the causes of accelerated corrosion, are subjected to various tests, including counteraction against local corrosion under conditions close to real in accordance with regulatory documents. [4, 5].

Due to the fact that the major producing assets of company are geographically located in Western Siberia, the parameters of the kinematic viscosity and pour point of the reagent are important and technologically significant. Under negative temperatures, the reagent must be pumped without any complications by the dosing pumps and must not freeze. Table 1 presents the main characteristics and requirements, in accordance with which laboratory testing of corrosion inhibitors is carried out.

Table 1. The list of physico-chemical properties and permissible ranges of parameters required for liquid corrosion inhibitors.

\begin{tabular}{|c|c|c|c|}
\hline No & Indicator & $\begin{array}{c}\text { Unit of } \\
\text { measurement }\end{array}$ & $\begin{array}{c}\text { Requirement for } \\
\text { the indicator }\end{array}$ \\
\hline 1 & Appearance & - & $\begin{array}{c}\text { Homogeneous, not } \\
\text { separate into } \\
\text { phases, without } \\
\text { sediment, } \\
\text { suspended and } \\
\text { settling particles }\end{array}$ \\
\hline 2 & $\begin{array}{c}\text { Kiscosity at minus } \\
40^{\circ} \mathrm{C}\end{array}$ & $\mathrm{MM}^{2} / \mathrm{c}$ & \begin{tabular}{c} 
No more than 800 \\
\hline 3
\end{tabular} \\
\hline 4 & Pour point & ${ }^{\circ} \mathrm{C}$ & $\begin{array}{c}\text { Not higher than } \\
\text { minus } 50\end{array}$ \\
\hline
\end{tabular}




\begin{tabular}{|c|c|c|c|}
\hline & $\begin{array}{c}\text { corrosion } \\
\text { inhibitors with } \\
\text { produced water }\end{array}$ & & \\
\hline 5 & $\begin{array}{c}\text { Compatibility of } \\
\text { corrosion } \\
\text { inhibitors with a } \\
\text { sample of oil }\end{array}$ & - & Compatible \\
\hline 6 & Protective effect & $\%$ & Not less than 90 \\
\hline
\end{tabular}

Conducting laboratory testing, first of all, those physicochemical characteristics are determined that have limits of using corrosion inhibitors. The laboratorytesting program for corrosion inhibitors is designed so that if the reagent does not meet the requirements for any parameter, this chemical reagent is not allowed for further testing and field tests. All reagents are tested under the same conditions for the same parameters in order to compare them and select the most effective ones.

In addition to the indicators from Table 1, a followup studies are conducted. Including determination of density at $20^{\circ} \mathrm{C}$, mass fraction of nonvolatile substances, amine number of unbound ions and concentration of hydrogen ions $(\mathrm{pH})$. Comparative tables are formed according to the results of laboratory tests.

Thus, laboratory testing of corrosion inhibitors is an algorithm for the systematic determination of the compliance of test reagents with technical requirements for corrosion inhibitors. Reagents that have successfully passed the stage of laboratory testing are recommended to participate in field trials.

\subsection{Implementation of the standard for pilot testing of chemical reagents in the Company}

In order to regulate the procedure of field tests, the Company developed and approved the «Experimental tests of chemical reagents for technological processes of extraction, collection and transportation of hydrocarbons» standard. A working group is formed to carry out the field tests. Objects are selected for conducting field tests, criteria for evaluating the results of field tests are defined, and PGI programs are developed with a work plan that includes milestones, deadlines.

At the stage of field test: the technology of applying corrosion inhibitors is adapted at a specific facility, effective dosages of the tested reagents are identified, recommendations for industrial use are developed. Only reagents that have successfully passed both stages of laboratory and experimental tests are allowed to industrial applications. The decision to allow industrial use of reagents is taken at the Scientific and Technical Council of the Gazprom Neft JSC (STC). In order to expand the base of effective reagents, a line of corrosion inhibitor effectiveness is updated every 5 years.

\section{Conclusion}

The implemented approach brought significant business impact. As a result of the work done to study the problems of corrosion on oilfield equipment, the development of rules and procedures for testing, technologies and related chemical agents in JSC Gazprom Neft, the problem with corrosion has become controlled. In the extractive subsidiaries of Gazprom Neft JSC, there has been an expansion of the range of corrosion inhibitors and reduction in basic dosages, which led to a decrease in the unit cost of inhibitor protection by more than $30 \%$ due to the selection of highly efficient and cost-effectiveness of reagents. As a result, the number of failures of oilfield equipment has significantly decreased

\section{References}

1. Saakyan L.S., Efremov A.P., Sobolev I.A. Improving the corrosion resistance of oil and gas equipment: Nedra, 1988. $231 \mathrm{p}$.

2. GOST 5272-68. «CORROSION OF METALS. Terms»

3. Rosenfeld I.L. Corrosion inhibitors: Chemistry, $1978.352 \mathrm{p}$.

4. ASTM G 184-06 «Standard Practice for Evaluating and Qualifying Oil Field and Refinery Corrosion Inhibitors Using Rotating Cage».

5. ASTM G202-12 «Standard Test Method for Using Atmospheric Pressure Rotating Cage». 